\title{
Growth rates of icicles
}

\author{
N. MAENo, \\ Institute of Low Temperature Science, Hokkaido University, Sapporo 060, Japan
}

L. MAKKONEN,

Laboratory of Structural Engineering, Technical Research Center of Finland, 02150 Espoo, Finland

K. NISHIMURA, Institute of Low Temperature Science, Hokkaido University, Sapporo 060, Japan

\author{
K. Kosugi, \\ Shinjo Branch of Snow and Ice Studies, National Research Institute for Earth Science and Disaster Prevention, Shinjo, \\ ramagata 996, Japan
}

T. TAKAHASHI

Hokkaido University of Education, Sapporo 002, Japan

\begin{abstract}
Experimental and theoretical studies on the growth rate of an icicle were carried out as a function of temperature, water-supply rate and wind speed; the relative humidity was also taken into account. The length of an icicle increases by the downward growth of thin dendritic crystals into the supercooled pendant water drop at the tip, and thus the growth is in the crystallographic $a$-axis direction. The diameter, on the other hand, increases by the freezing of a water film flowing down along the icicle wall. The ratio of measured length- and diameter-growth rates was large, namely $8-32$.

Both growth rates increased with decreasing temperature and increasing wind speed. The increase in water-supply rate led to the decrease in the length-growth rate but no significant change in the diameter-growth rate. These results could be well described by a numerical model of icicle growth which takes account of the dendritic growth at the tip and the wall and the effective heat transfer within the turbulent boundary layer around the icicle. A formation mechanism of ribs and hollows is discussed in relation to the flowing and freezing process of water on an icicle wall.
\end{abstract}

\section{INTRODUGTION}

Icicles form wherever cold water flows from an overhanging substrate at temperatures below the freezing point of water. Though varieties of icicles have been noticed and described in the many literatures in all snow countries of the world, few detailed studies of icicles have been undertaken. As summarized by Dorsey (1940), the crystalline structure was the first main subject of icicles studied by Leydolt (1851), Bertin (1878), McConnel and Kidd (1888), Futterer (1901), Hess (1904, 1933) and Yoshida and Tsuboi (1929); similar observations have been made by Laudise and Barns (1979) and Knight (1980). All these observations have not been quantitative and systematic but their conclusions on the crystalline structure of icicles are not in harmony.

The growth condition is definitely important to form the crystalline structure of an icicle. According to our observations, in particular calm conditions, an icicle can even develop as a monocrystal, but most icicles are polycrystalline to some extent, depending on their growth conditions. It can be said, however, that the crystallographic $c$ axis tends to be perpendicular to the icicle axis at the growing tip as shown below.

The growth mechanism of an icicle can be studied only by close observation of growing icicles; such studies were made by Hatakeyama and Nemoto (1958), Geer (1981) and Maeno and Takahashi (1984a,b). Hatakeyama and Nemoto noticed that, in some cases, an icicle grows with a tubular tip filled with water and sometimes with air bubbles. Geer confirmed that such a shape is always found in a growing tip. Maeno and Takahashi made systematic observations of natural icicles and carried out growth experiments on icicles in controlled conditions of temperature, water-supply rate and wind speed. Later, Makkonen (1988) formulated a theoretical model of icicle growth. The general conclusion found by the above four research groups was summarized by Walker (1988) without referring to the original literature.

The present paper reports recent measurements of growth rates of icicles formed in calm and windy 
conditions, and a comparison with results computed by a further-improved theoretical model.

\section{GROWTH MECHANISM OF AN ICICLE}

An icicle grows by an increase in its length at the tip and its diameter at the external surface. The two growth processes are very different in nature, although they proceed simultaneously. On the basis of the observation of many icicles growing in various natural conditions and being formed in laboratory-controlled conditions, Maeno and Takahashi (1984a) proposed a growth model schematically described in Figure 1. The growing tip of an icicle is a thin sheath tube filled with liquid water.

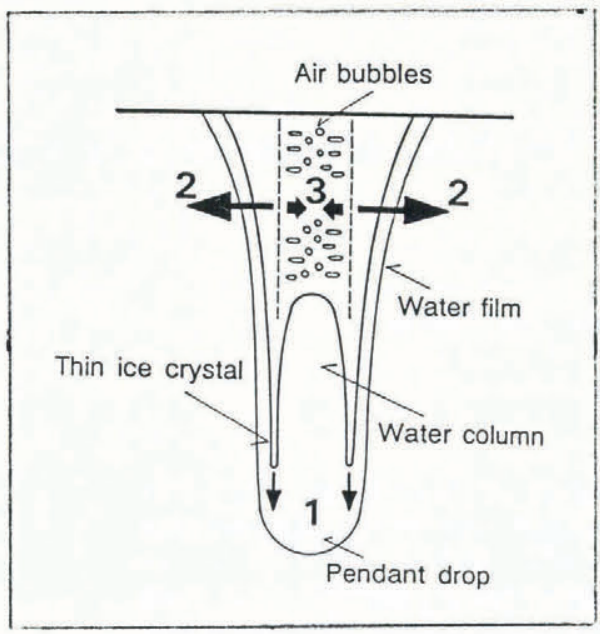

Fig. 1. Schematic picture of a vertical cross-section of a growing icicle. Three growth directions are described by arrows: 1. Downward growth at the tip; 2. Outward growth at the wall; 3. Inward growth by freezing of the water column captured in the center of an icicle.

The growing tip of an icicle is composed of a few thin, $0.1 \mathrm{~mm}$ thick or less, monocrystalline ice platelets as shown in Figure 2; the platelets grow dendritically, usually in the crystallographic $a$-axis direction, into a pendant supercooled water drop and are momentarily exposed to the surrounding cold air when the drop falls down periodically. The radius of the dripping drop $(r)$ is almost constant irrespective of temperature, $2.44 \mathrm{~mm}$ on

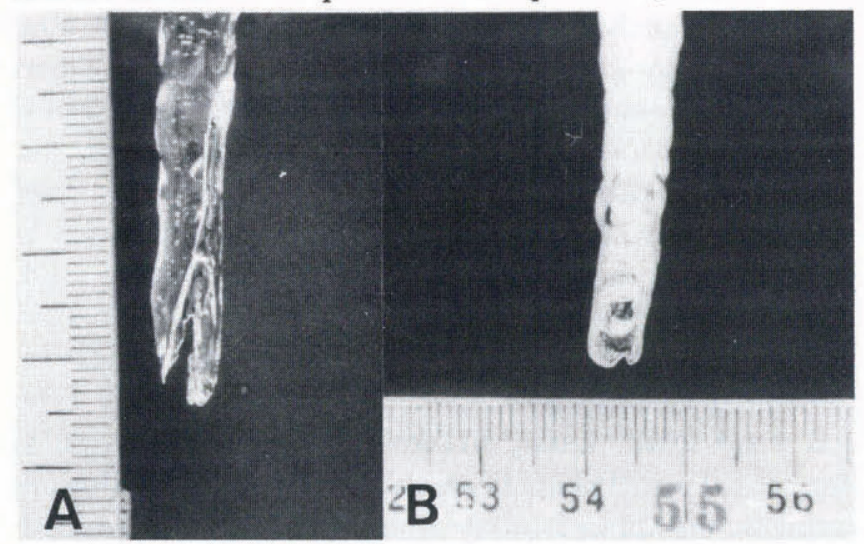

Fig. 2. Photographs showing the tip of a growing icicle. The unfrozen water in the sheath was shaken off. The smallest scale is $1 \mathrm{~mm}$. Photograph $B$ shows the inside of the icicle tip.

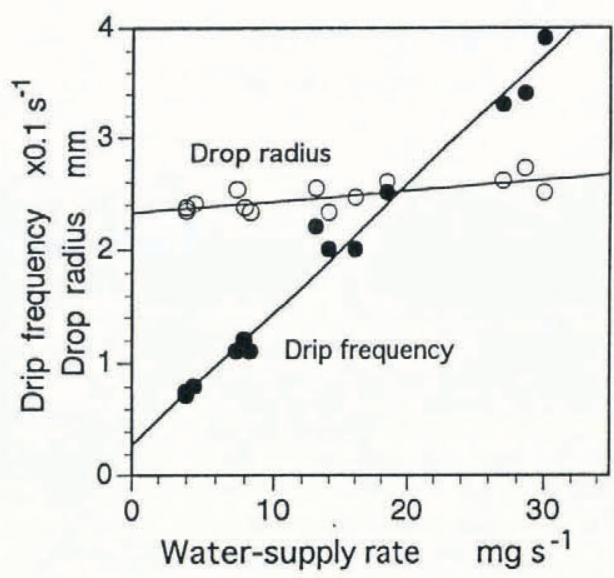

Fig. 3. Dripping frequency and drop radius versus watersupply rate at various temperatures $\left(-4^{\circ}\right.$ to $\left.-21^{\circ} \mathrm{C}\right)$.

average (Maeno and Takahashi, 1984a) but, as shown in Figure 3 and Table 1, it shows a slightly increasing tendency with water-supply rate $(W)$ :

$$
r=0.0098 W+2.33
$$

where the units of $r$ and $W$ are $\mathrm{mm}$ and $\mathrm{mg} \mathrm{s}^{-1}$, respectively. The dripping frequency of drops $(f)$ increases with $W$ but is a complex function of the growth process, since part of $W$ is lost by freezing. In our experimental conditions, $f$ could be empirically approximated as:

$$
f=0.0166 W+0.0281
$$

where the unit of $f$ is $\mathrm{s}^{-1}$, so that water in a pendant drop at the tip is replaced roughly once every 2-14s.

The average diameter of the unfrozen water column at the tip is $5.0 \mathrm{~mm}$, its length sometimes amounting to $5 \mathrm{~cm}$. The columnar water, captured in the icicle as a result of the growth of the tubular tip, freezes slowly in a radial direction towards the center, possibly after the cessation of the external icicle growth (Fig. 1). In the freezing process, fine ice spikes are often observed to grow from the surface of an icicle due to squeezing out and rapid freezing of water (Maeno and others, 1994). The radial freezing process is supported by the presence of many tiny air bubbles trapped at the central part of an icicle. Figure 4 gives microscopic photographs of thin horizontal and vertical sections of the central part; orientations of trapped air bubbles are almost radial and horizontal, and their forms and sizes are more spherical and thicker towards the center of the icicle. The former suggests that the captured water column freezes radially and horizontally from the outer surface inward, and the latter that its freezing rate is reduced and the concentration of air dissolved in the water becomes larger approaching the center (Maeno, 1967). Such a growth manner of an icicle seems completely similar to that of a tubular stalactite (Moore and Nicholas, 1964) but it is different in that the liquid solution is supplied to the stalactite by downward flow inside its tube and never fills up the tube like an icicle.

It is concluded that icicle growth can be divided into three processes, namely the increase in length by the downward growth at the tip, increase in diameter by outward radial freezing of a flowing film of water and the 


\begin{tabular}{|c|c|c|c|c|c|c|c|c|c|c|c|}
\hline $\begin{array}{l}\text { Run } \\
\text { number }\end{array}$ & $\begin{array}{c}\text { Temper- } \\
\text { ature } \\
T_{a} \\
{ }^{\circ} \mathrm{C}\end{array}$ & $\begin{array}{l}\text { Water- } \\
\text { supply } \\
\text { rate } W \\
\mathrm{mg} \mathrm{s}^{-1}\end{array}$ & $\begin{array}{c}\text { Humidity } \\
R\end{array}$ & $\begin{array}{l}\text { Wind } \\
\text { speed } U \\
\mathrm{~m} \mathrm{~s}^{-1}\end{array}$ & $\begin{array}{l}\text { Growth } \\
\text { rate of } \\
\text { length } \\
\mathrm{cm} \mathrm{h}^{-1}\end{array}$ & $\begin{array}{l}\text { Growth } \\
\text { rate of } \\
\text { diameter } \\
\mathrm{cm} \mathrm{h}^{-1}\end{array}$ & $\begin{array}{c}\text { Length } \\
L\end{array}$ & $\begin{array}{c}\text { Diameter } \\
D\end{array}$ & $\begin{array}{c}\text { Duration } \\
\text { of growth } \\
\text { min }\end{array}$ & $\begin{array}{c}\text { Dripping } \\
\text { frequency } \\
\qquad f \\
\mathrm{~s}^{-1}\end{array}$ & $\begin{array}{c}\text { Drop } \\
\text { radius } \\
\quad r \\
\mathrm{~mm}\end{array}$ \\
\hline 8401 & -5 & 4 & - & 0 & 3.7 & - & 13 & 0.5 & 180 & 0.071 & 2.37 \\
\hline 8402 & -5.5 & 4 & - & 0 & 3.5 & 0.3 & 18 & 1 & 270 & 0.074 & 2.34 \\
\hline 8403 & -4.9 & 13 & - & 0 & 3.3 & 0.38 & 12.5 & 0.5 & 240 & 0.22 & 2.54 \\
\hline 8404 & -10.4 & 4 & - & 0 & 12.5 & 0.38 & 25 & 0.9 & 100 & 0.071 & 2.37 \\
\hline 8405 & -9.4 & 8 & - & 0 & 7 & 0.47 & 28 & 1.5 & 240 & 0.12 & 2.37 \\
\hline 8406 & -10 & 14 & - & 0 & 6.5 & 0.48 & 27 & 1.5 & 240 & 0.2 & 2.33 \\
\hline 8407 & -10.5 & 27 & - & 0 & 4.7 & 0.47 & 21 & 1.4 & 210 & 0.33 & 2.61 \\
\hline 8408 & -15.9 & 4.6 & - & 0 & 19 & - & 13 & 0.6 & 30 & 0.079 & 2.4 \\
\hline 8409 & -16 & 7.5 & - & 0 & 16.8 & 0.65 & 19 & 0.6 & 60 & 0.11 & 2.53 \\
\hline 8410 & -14.6 & 18.4 & - & 0 & 10.2 & 0.68 & 36 & 1.6 & 180 & 0.25 & 2.6 \\
\hline 8411 & -15.4 & 28.6 & - & 0 & 6.4 & 0.63 & 26 & 1.9 & 180 & 0.34 & 2.72 \\
\hline 8412 & -20 & 8.4 & - & 0 & 22.4 & 0.95 & 13 & 0.4 & 40 & 0.11 & 2.33 \\
\hline 8413 & -20.3 & 16 & - & 0 & 14 & 1 & 24 & 1.2 & 90 & 0.2 & 2.46 \\
\hline 8414 & -18.7 & 30 & - & 0 & 10.8 & 1 & 35 & 3 & 150 & 0.39 & 2.5 \\
\hline 8901 & -11.2 & 7.11 & 73.6 & 0 & 8.21 & 0.43 & 14.7 & 0.8 & 120 & - & - \\
\hline 8902 & -11.8 & 8.77 & 74 & 0 & 12.42 & 0.33 & 22.8 & 0.9 & 160 & - & - \\
\hline 8903 & -11.6 & 11.9 & 73.7 & 0 & 9.58 & 0.282 & 27.8 & 1.2 & 180 & - & - \\
\hline 8904 & -12 & 29.6 & 71.7 & 0 & 6.3 & 0.306 & 20.2 & 1.3 & 180 & - & - \\
\hline 8905 & -11 & 29.6 & 75.6 & 0 & 5.41 & 0.276 & 21.1 & 1.4 & 240 & - & - \\
\hline 8906 & -10.7 & - & - & 1.5 & - & - & - & - & - & - & - \\
\hline 8907 & -9.4 & 8.8 & 76.2 & 1.5 & 31.92 & 2.1 & 11.5 & 0.7 & 20 & - & - \\
\hline 8908 & -11.6 & 9.4 & 79.4 & 1.5 & 38.52 & 1.74 & 6.9 & 0.4 & 10 & - & - \\
\hline 8909 & -10.9 & 31.9 & 77.9 & 5 & 34.08 & 4.2 & 21.5 & $2.6,0.8^{*}$ & 40 & - & - \\
\hline 8910 & -12.8 & 28.1 & 76.5 & 1.5 & 25.32 & 4.18 & 32.7 & $4.1,0.7^{*}$ & 80 & - & - \\
\hline 8911 & -9.2 & 4.7 & 72.7 & 5 & 25.2 & 1.6 & - & - & - & - & - \\
\hline 8912 & -8.6 & 11.3 & 78.1 & 5 & 47.4 & 3 & 7.9 & 0.5 & 10 & - & - \\
\hline 8913 & -10.6 & 10.3 & 73.4 & 5 & 79.2 & 2 & 6.6 & 0.5 & 5 & - & - \\
\hline 8914 & -9.9 & 67.7 & 77.7 & 5 & 18.45 & 1.49 & 27.1 & $5.0,0.8^{*}$ & 50 & - & - \\
\hline $8915-1$ & -27.6 & 34.8 & 67.6 & 0 & 14.04 & 0.42 & 10.5 & 0.8 & 40 & - & - \\
\hline $8915-2$ & -28.8 & 34.8 & 68.5 & 0 & 23.61 & 1.05 & 31.3 & 1.7 & 100 & - & - \\
\hline $8916^{\dagger}$ & -11.4 & 10.1 & 78.7 & 0 & 6.12 & 0.49 & 18.4 & 1.7 & 180 & - & - \\
\hline
\end{tabular}

* Long and short diameters of flat icicles.

$\dagger$ Run 8916 is the icicle-formation experiment from an $\mathrm{NaCl}$ solution of 3.2 weight per cent.

inward radial freezing of a water column captured at the central axis of an icicle. The three growth directions are described by arrows in Figure 1.

\section{MEASUREMENTS OF ICICLE-GROWTH RATES}

Growth rates of icicles were measured as functions of temperature $\left(0\right.$ to $\left.-30^{\circ} \mathrm{C}\right)$, water-supply rate $(0-30 \mathrm{mg}$ $\mathrm{s}^{-1}$ ) and wind speed $\left(0-5 \mathrm{~m} \mathrm{~s}^{-1}\right)$. The experimental system is similar to that used by Maeno and Takahashi (1984a), except that in the present experiment the mass of an icicle and the relative humidity of the surrounding atmosphere were simultaneously monitored. The temperature of the water supplied was kept a few degrees above $0^{\circ} \mathrm{C}$ by a band-type heater wrapped over the water-supply tube.
Icicles were grown from a wet gauze wound over a metal bar. All the measurements were carried out in a cold room, the temperature of which could be varied between $0^{\circ}$ and $-30^{\circ} \mathrm{C}$.

Figure 5 gives typical examples of the time evolution of icicles at a temperature around $-10^{\circ} \mathrm{C}$. At a fixed temperature and water-supply rate, icicle lengths and diameters generally increase almost linearly with time but diameters show a decreasing trend in their later stage. The increase in the water-supply rate $(W)$ leads to a decrease in the growth rates of length as shown by run $8903\left(W=11.9 \mathrm{mg} \mathrm{s}^{-1}\right)$ and run $8905\left(W=29.6 \mathrm{mg} \mathrm{s}^{-1}\right)$ in Figure 5 a but a decreasing relationship is not so clear in the growth rate of the diameter (Fig. 5b). Such a result was similarly observed at other temperatures, though lower temperatures led to a decrease in both of the rates (Maeno and Takahashi, 1984a). 


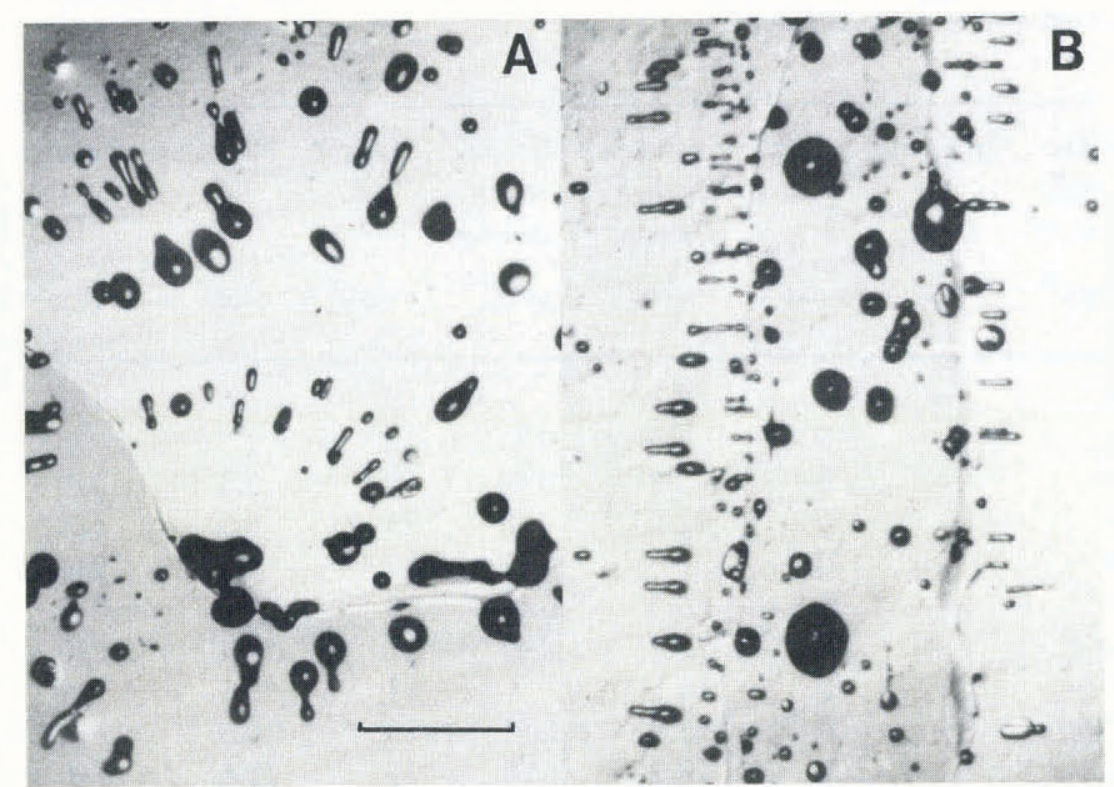

Fig. 4. Thin cross-sections of the center of an icicle in crossed polarized light. A. Horizontal section; B. Vertical section. The scale is $1 \mathrm{~mm}$.

The general result is summarized in Figure 6, which gives observed growth rates of length or diameter by solid symbols as functions of water-supply rate and air temperature; open symbols are the results computed and will be discussed later. As shown in Figure 6, the growth rate of the length is 8-32 times larger than that of the diameter, and the former decreases with an increasing water-supply rate but the latter does not and maintains almost similar values depending on temperature. The almost-constant growth rate of diameter with increasing water-supply rate is explained by a similar supercooling achieved because the thickness of the flowing water film does not change much, as discussed below, and also by a decrease in the heat-transfer coefficient with increasing length (Makkonen, 1988).

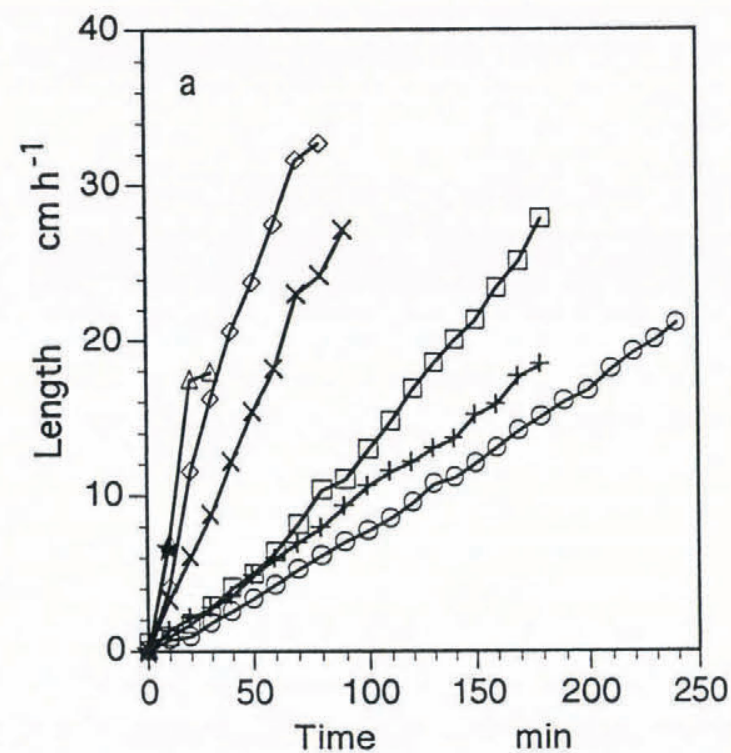

Figure 5 shows that an increase in the wind speed leads to an increase in growth rates of length and diameter; compare run 8903 (wind speed $U=0 \mathrm{~m} \mathrm{~s}^{-1}$ ) with run $8908\left(U=1.5 \mathrm{~m} \mathrm{~s}^{-1}\right)$ and run $8913(U=5.0$ $\mathrm{m} \mathrm{s}^{-1}$ ). The decrease in the length-growth rate by the increase in the water-supply rate is even clearer in windy conditions; compare run $8908\left(W=9.4 \mathrm{mg} \mathrm{s}^{-1}, U=1.5\right.$ $\left.\mathrm{m} \mathrm{s}^{-1}\right)$ with run $8910\left(W=28.1 \mathrm{mg} \mathrm{s}^{-1}, U=1.5 \mathrm{~m} \mathrm{~s}^{-1}\right)$, or run $8913\left(W=10.3 \mathrm{mg} \mathrm{s}^{-1}, U=5.0 \mathrm{~m} \mathrm{~s}^{-1}\right)$ with run 8914 $\left(W=67.7 \mathrm{mg} \mathrm{s}^{-1}, U=5.0 \mathrm{~m} \mathrm{~s}^{-1}\right)$ in Figure $5 \mathrm{a}$. On the other hand, the diameter-growth rate gives almost similar values at different wind speeds (Figs $5 \mathrm{~b}$ and $6 \mathrm{~b}$ ).

One saline icicle was grown from an $\mathrm{NaCl}$ solution (3.2 weight per cent) in calm conditions (run 8916 in Figure 5). Average concentrations of the whole icicle and

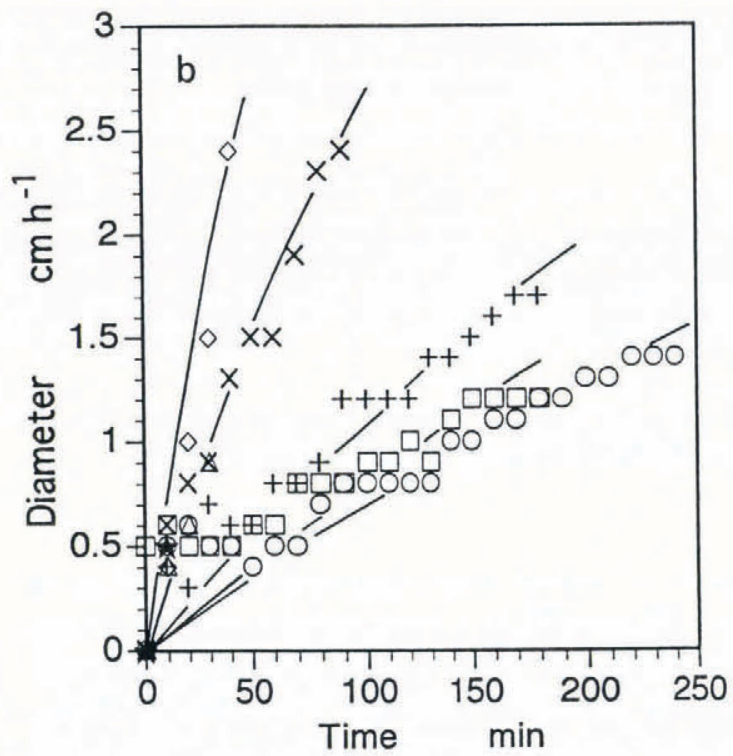

Fig. 5. Time evolution of the length and diameter of an icicle at a temperature around $-10^{\circ} \mathrm{C} . a$ : Length; $b$ : Diameter. $\square$ :run $8903\left(T=-11.6^{\circ} \mathrm{C}, W=11.9 \mathrm{mg} \mathrm{s}^{-1}, U=0 \mathrm{~m} \mathrm{~s}^{-1}\right) ; 0:$ run $8905(-11.0,29.6,0) ; \Delta:$ run 8908 (-11.6, 9.4, 1.5); $\diamond: r u n 8910(-12.8,28.1,1.5)$; $\star$ :run $8913(-10.6,10.3,5.0) ;$ X:run $8914(-9.9,67.7,5.0)$; +:run 8916 $(-11.4,10.1,0, \mathrm{NaCl}$ solution of 3.2 weight per cent $)$. 

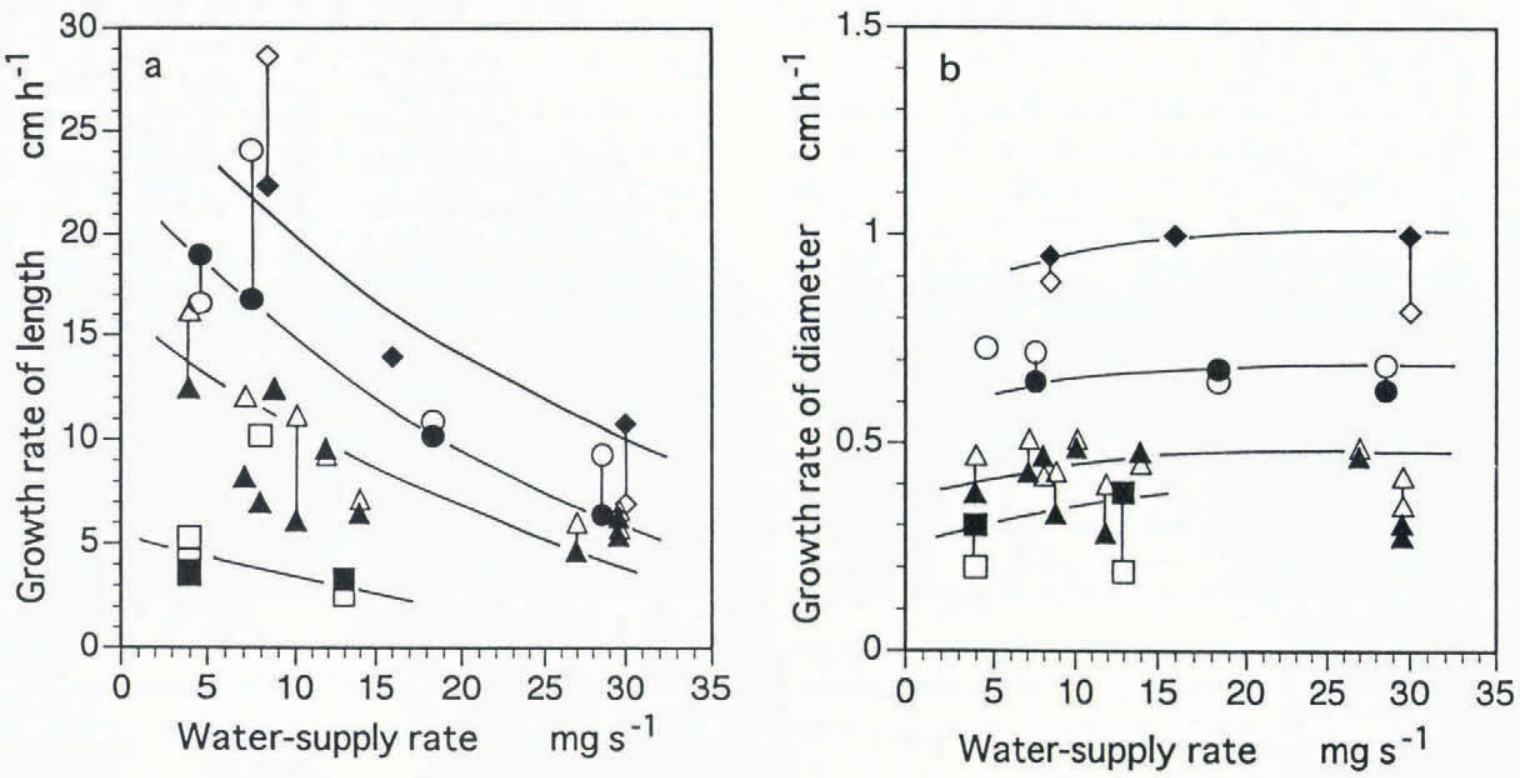

Fig. 6. Growth rates of icicles versus water-supply rate in calm conditions. a. Length; b. Diameter. $\square: T=-4^{\circ}$ to $-6^{\circ} \mathrm{C}, \mathbf{\Delta} \Delta: T=-9^{\circ}$ to $-11^{\circ} \mathrm{C}, \bigcirc: T=-14^{\circ}$ to $-16^{\circ} \mathrm{C}, \diamond \diamond: T=-18^{\circ}$ to $-20^{\circ} \mathrm{C}$. In each pair of data, solid and open symbols refer to measured and calculated rates, respectively.

its tip part were 1.7 and $9.2 \%$, respectively. The concentration of the dripping solution was $4.0 \%$. The impurity addition decreased the growth rate of length but increased that of diameter; cf. those with run 8903 . This result is reasonable and confirms that of Chung and Lozowski (1990).

\section{NUMERICAL SIMULATION OF IGICLE GROWTH}

A numerical simulation of the growth of an icicle was done on the basis of the model proposed by Makkonen (1988), to which new developments were made in two points. The model calculates the growth rates of length and diameter simultaneously from the following heatbalance equations at the tip and at the wall:

$$
q_{\mathrm{conv}}+q_{\mathrm{evap}}+q_{\mathrm{rad}}=q_{\mathrm{drip}}+q_{\mathrm{freez}}
$$

at the tip, and

$$
q_{\text {conv }}+q_{\text {evap }}+q_{\text {rad }}=q_{\text {freez }}
$$

at the wall, where $q_{\text {conv }}, q_{\text {evap }}$ and $q_{\text {rad }}$ are heat losses caused by convection, evaporation of water and radiation, respectively, and $q_{\text {freez }}$ is the latent heat released by freezing of water. The term, $q_{\text {drip }}$, is only required in the heat balance at the tip, which evaluates the net heat carried by flowing-in and dripping water, since water flowing into the pendant drop leaves at a slightly lower temperature.

Each term in Equations (3) and (4) was reasonably formulated at both the tip and the wall, giving two heatbalance equations (equations (16) and (22); Makkonen, 1988) for the two unknown growth rates of length and diameter $\left(u_{\mathrm{L}}, u_{\mathrm{D}}\right)$ at each instant, as functions of the length $(L)$, diameter $(D)$, air temperature $\left(T_{\mathrm{a}}\right)$, relative humidity $(R)$, water-supply rate $(W)$ and convective heat-transfer coefficients $\left(h_{\mathrm{L}}\right.$ at the tip and $h_{\mathrm{W}}$ at the wall). $h_{\mathrm{L}}$ and $h_{\mathrm{W}}$ are functions of the wind speed $(U)$ and the icicle sizes $(L$ and $D)$. The two growth equations are cross-related and are solved numerically to give $u_{\mathrm{L}}$ and $u_{\mathrm{D}}$ at each time step.

One of the two refinements to the model made in this paper is the parameterization of the wall thickness at the tip. The thickness of the growing dendritic ice platelet was assumed constant at $75 \mu \mathrm{m}$ by Makkonen (1988). This gives quite reasonable results but, in principle, it is more accurate to adopt the recent data on the relationship between the supercooling of water $(\Delta T)$ and the radius $\left(r_{t}\right)$ of the growing dendrite, whose shape is an elliptic paraboloid (Tirmizi and Gill, 1987):

$$
r_{\mathrm{t}} \Delta T=0.88 \times 10^{-6}
$$

where the units of $r_{\mathrm{t}}$ and $\Delta T$ are $\mathrm{m}$ and ${ }^{\circ} \mathrm{C}$, respectively. The problem with using Equation (5) is that the effective length of the dendrite must be assumed in order to estimate the effective dendrite width by the tip radius $r_{\mathrm{t}}$ and the parabolic geometry. We used the approximation that the length is $100 r_{t}$, because this will give a reasonable length in relation to the drop height. This particular assumption is not critical to the model results.

Another improvement is the dependence of the $a$-axis dendritic growth rate $\left(u_{0}\right)$ on supercooling. The old Hillig-Turnbull's equation, equation (8) in Makkonen (1988), was replaced by a recent result (Timizi and Gill, 1987):

$$
u_{0}=1.87 \times 10^{-4}(\Delta T)^{2.09}
$$

for $\Delta T>0.2^{\circ} \mathrm{C}$, and

$$
u_{0}=3.52 \times 10^{-5}(\Delta T)^{1.06}
$$

for $0.05<\Delta T<0.2^{\circ} \mathrm{C}$ where the unit of $u_{0}$ is $\mathrm{m} \mathrm{s}^{-1}$. As to the dendritic growth in the flowing water film on the wall, Equation (6) was adopted by assuming a certain angle of growth, namely $1^{\circ}$, i.e. almost vertical, to take account of the effect of water flow on the growth direction in the spongy ice. This assumption is artificial and affects the model results at high drip rates. 
In Figure 6, growth rates of length and diameter calculated by the model are plotted as open symbols at various water-supply rates and temperatures; measured and computed data, in pairs, are connected by lines. In the computation, a relative humidity of $80 \%$ was assumed. Though it was not measured in the experiment (Maeno and Takahashi, 1984a), the magnitude was confirmed as reasonable by a subsequent measurement. The computed and measured rates are not in complete agreement but the calculation gives the reasonable dependence on water-supply rate and temperature.

Computed growth rates of length and diameter in windy conditions are given by the curves in Figure 7; calculations were made at a temperature of $-10^{\circ} \mathrm{C}$ and humidity of $75 \%$, though the actual temperature and humidity of the experiment shown in Figure 7 ranged from $-8.6^{\circ}$ to $-12.8^{\circ} \mathrm{C}$ and from 71 to $79 \%$, respectively. The effect of wind is large as expected, and at a wind speed of $U=1.5 \mathrm{~m} \mathrm{~s}^{-1}$ the calculated values are in close agreement with those measured. However, at $U=5.0 \mathrm{~m} \mathrm{~s}^{-1}$, the growth rates do not increase much in the experiment, in contrast to the large increase in the calculation. The following experimental observation should be noteworthy: that strong winds often cause irregular flowing, dripping and freezing of water. Winds raise the heat transfer, especially to windward but strong winds tend to carry away water leeward, both resulting in a difference in freezing rate to windward and leeward, and leading to the heterogeneous growth of icicles. Thus, icicles will be flat in the wind direction and sometimes bent by the wind effect on the water drop at the tip, as discussed by Maeno and Takahashi (1984b) and Maeno and others (1994).

Figure 8 gives the computed length and diameter plotted against measured ones; computations were made for the time period of steady growth in each measurement
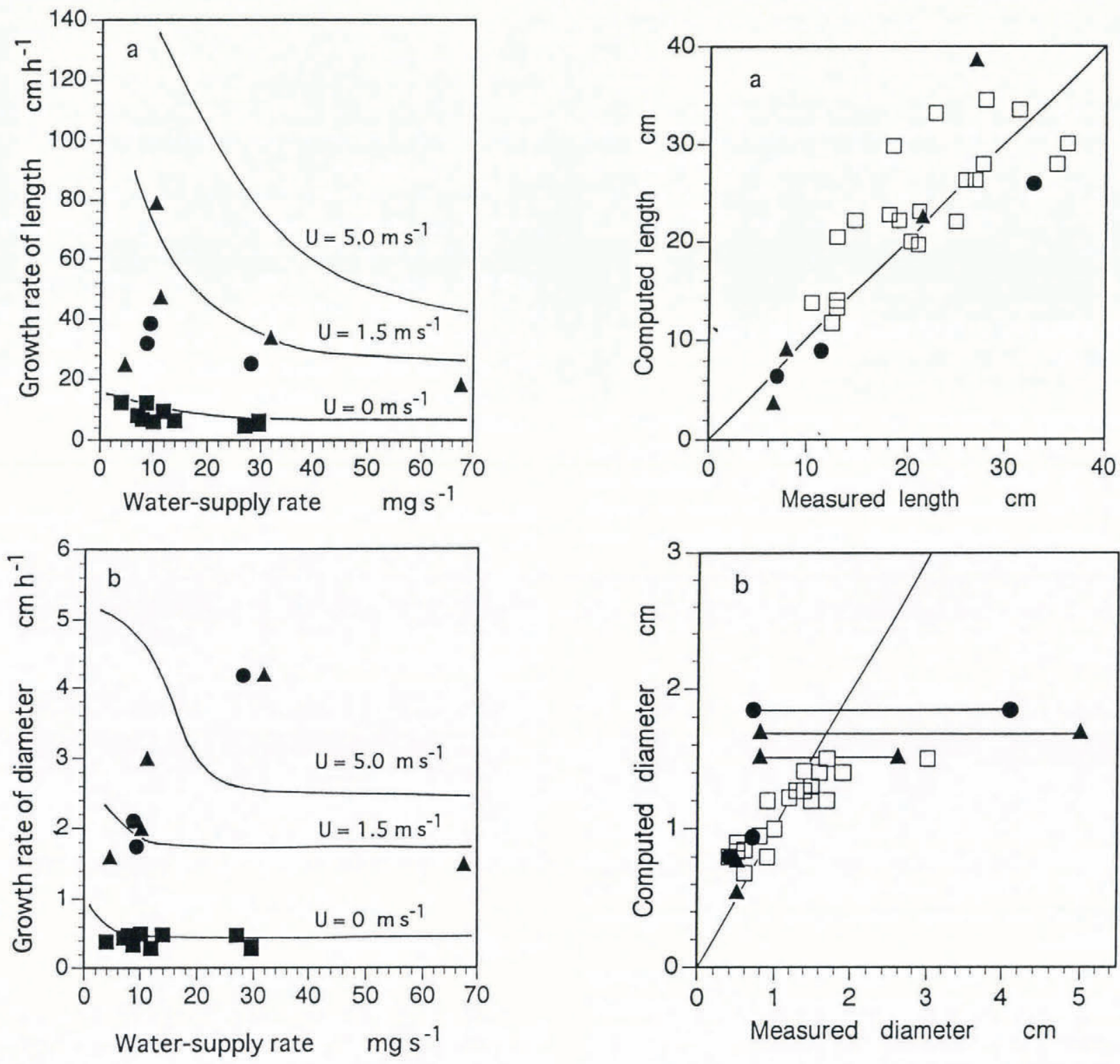

Fig. 7. Growth rates of icicles versus water-supply rate at a temperature around $-10^{\circ} \mathrm{C}$. a. Length, b. Diameter. 口: $U=0 \mathrm{~m} \mathrm{~s}^{-1}, \mathbf{0}: U=1.5 \mathrm{~ms}^{-1}, \mathbf{\Delta}: U=5.0 \mathrm{~m} \mathrm{~s}^{-1}$. The curves are calculated rates in conditions $T=-10^{\circ} \mathrm{C}$, $R=75 \%$, and $U=0,1.5$ and $5.0 \mathrm{~m} \mathrm{~s}^{-1}$.

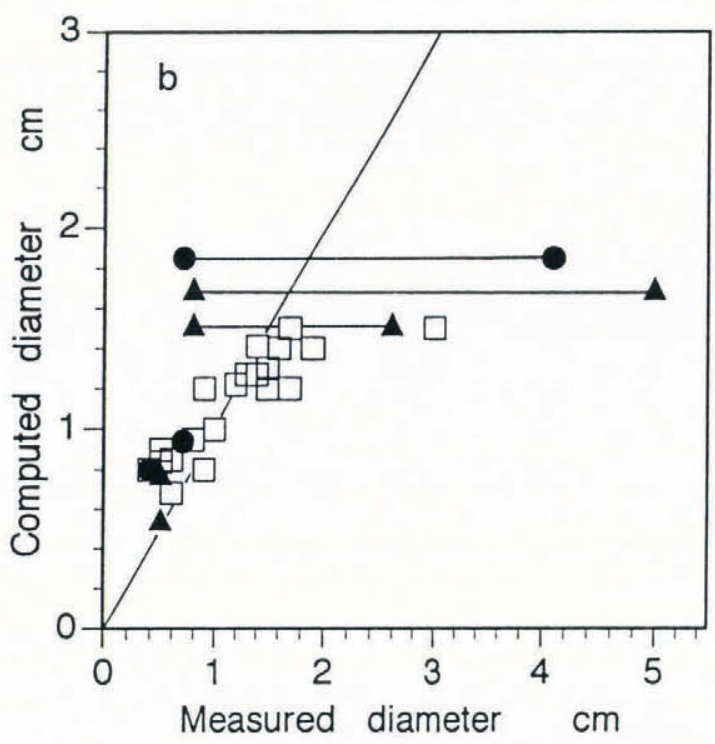

Fig. 8. Comparison of calculated and measured length and diameter of an icicle. a. Length, b. Diameter, $\square: U=0$ $\mathrm{ms}^{-1}, \mathbf{0}: u=1.5 \mathrm{~ms}^{-1}, \mathbf{\Delta}: U=5.0 \mathrm{~m} \mathrm{~s}^{-1}$. Pair data connected with lines give long and short diameters of flat icicles. 
(Table 1). In spite of some discrepancies noted in the growth rates (Figs 6 and 7), a reasonable agreement is recognized between the computed and measured lengths and diameters. It should be noted in Figure $8 \mathrm{~b}$ that the computation was made assuming uniform flow and freezing of water on a spherical wall, although the actual flow and freezing are often irregular and heterogeneous especially in icicles growing in windy conditions. In these cases, the horizontal cross-sections of icicles tend to deviate from a circular form, leading to flat or streamlined icicles, described above (Maeno and Takahashi, 1984b; Maeno and others, 1993). In Figure 8b, pair data connected with lines give long and short diameters of icicles grown in wind speeds of 1.5 and $5 \mathrm{~m} \mathrm{~s}^{-1}$.

\section{DISGUSSION}

As the Reynolds number of water flowing along the wall of an icicle is roughly $0.15-3.6$ in ordinary icicleformation conditions (Maeno and Takahashi, 1984a), the flow is laminar and its mean thickness $(\delta)$ is expressed as the following Nusselt equation (Duckler and Bergelin, 1952):

$$
\delta=\left(3 \eta Q / \rho^{2} g\right)^{\frac{1}{3}}
$$

where $Q$ is the mass-flow rate per unit width and time, i.e. $W / \pi D, \eta$ and $\rho$ are the viscosity and density of water and $g$ is the acceleration of gravity. It is shown from Equation (7) that the thickness of a flowing water film increases only slowly with $Q$ or $W, \delta$ increasing from 40 to only 80 $\mu \mathrm{m}$ when $W$ increases from 5 to $30 \mathrm{mg} \mathrm{s}^{-1}$ (the range of our icicle experiment). As mentioned above, the almost constant thickness is partly responsible for the independence of the diameter-growth rate on the water-supply rate (Figs $6 \mathrm{~b}$ and $7 \mathrm{~b}$ ). In contrast to the thickness, the mean flow velocity of the water film increases more rapidly, its magnitude increasing from $0.3 \mathrm{~cm} \mathrm{~s}^{-1}$ at $W=5 \mathrm{mg} \mathrm{s}^{-1}$ to $1.2 \mathrm{~cm} \mathrm{~s}^{-1}$ at $W=30 \mathrm{mg} \mathrm{s}^{-1}$ (Maeno and Takahashi, 1984a); therefore, the water flow transports heat more effectively to the icicle tip, resulting in a decrease in the length-growth rate with an increasing water-supply rate.

Water flow on an actual icicle wall, however, is by no means smooth or regular, and hence the freezing process is irregular and complicated. One of its effects is the wavy pattern or horizontal ribbing often found on many icicles (Fig. 9A). The ribs are protruded rings where ice formed by fast freezing of water, and the hollows by slow freezing. It is recognized in the vertical thin section of an icicle (Fig. 9B) that many tiny air bubbles are trapped in the ribs and that the ribs migrate slightly upward during growth.

The formation of ribs and hollows can be explained as follows (Maeno and Takahashi, 1984b). The irregular water flow on an icicle wall is unstable and tends to allow accidentally formed small protrusions to develop preferentially through the following three processes. First, though the mean thickness of the flowing water film may be expressed by Equation (7), it may be thinner at protrusions, resulting in faster cooling and hence freezing
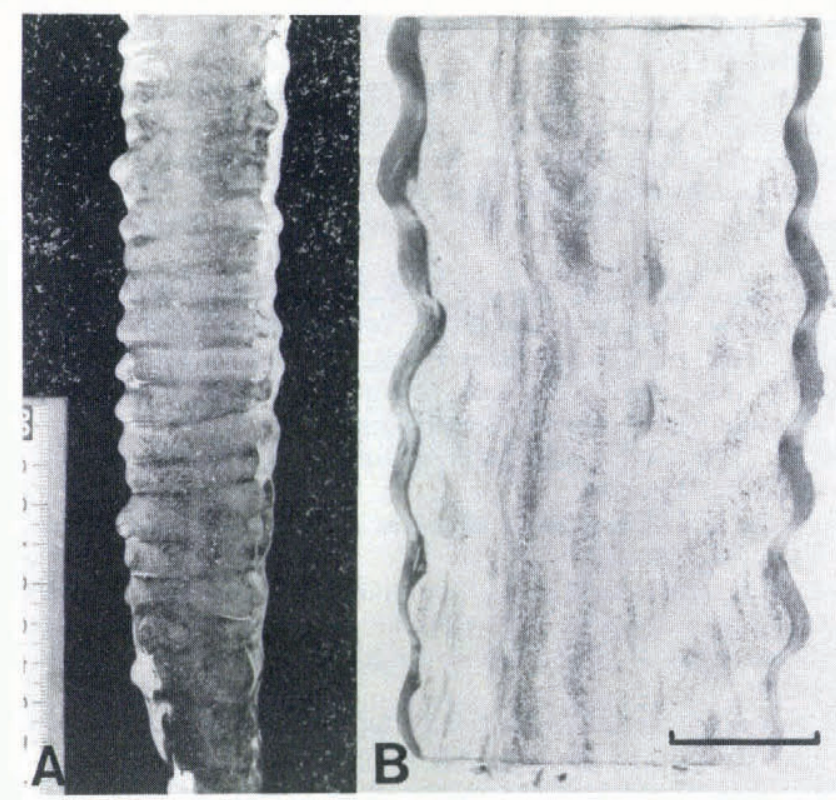

Fig. 9. Photographs of icicles with periodic ribs and hollows. The smallest scale in $A$ is $1 \mathrm{~mm} . B$ is a photograph showing a vertical thin cross-section (the scale is $2 \mathrm{~cm}$ ).

to promote rib formation. Secondly, the protrusions are more exposed to the surrounding cold air so that heat transfer and evaporation are more effective, causing faster ice growth on ribs. Thirdly, the flowing water, which is more viscous than ordinary water due to the minute ice crystals it contains, just as frazil ice in cold river and sea water, tends to be stagnant just upstream of ribs. The situation will lead to slightly upward ice growth at the ribs and the formation of a hollow, that is the region of slower ice growth, between the ribs.

According to a statistical analysis of many ribs of icicles in Sapporo (Maeno and Takahashi, 1984b), the spacing between ribs clearly gives a normal distribution. The mean is $9.0 \mathrm{~mm}$ with $70 \%$ contained in a range 7.0 $11.0 \mathrm{~mm}$. Ribs are more frequently formed near the growing tips than the roots. It was somewhat difficult to grow icicles with significant ribs in the steady calm conditions of icicle formation. These findings suggest that the formation of ribs requires a specific condition which might be, for example, the time variation in temperature, wind or water-supply rate.

\section{ACKNOWLEDGEMENTS}

This work was partly supported by grants-in-aid for Research in Natural Disaster, Japanese Co-operative Research and Scientific Research of the Ministry of Education, Science and Culture.

\section{REFERENCES}

Bertin, A. 1878. Sur la structure optique de la glace. Annales de Chimie et de Physique, 5(13), 283-288.

Chung, K. K. and E. P. Lozowski. 1990. On the growth of marine icicles. Atmosphere-Ocean, 28(4), 393-408. 
Dorsey, N.E. 1940. Properties of ordinary water-substance. New York, Reinhold Pub. Corp.

Duckler, A. E. and O. P. Bergelin. 1952. Characteristics of flow in falling liquid film. Chem. Eng. Prog., 48(11), 557-563.

Futterer, K. 1901. Ueber die Struktur der Eiszapfen. Bericht des Oberrheinischen Geologischen Vereins, 34, 1-4.

Geer, I.W. 1981. The not-so-ordinary icicle. Weatherwise, 34(6), 257-259.

Hatakeyama, H. and S. Nemoto. 1958. A note on the formation of horizontal stripes on icicles. Geophys. Mag., 28(4), 477-482.

Hess, H. 1904. Die Gletscher. Braunschweig, Friedrich Vieweg und Sohn.

Hess, H. 1933. Das Eis der Erde. In Gutenberg, B., ed. Handbuch der Geophysik. Berlin, Gebrüder Borntraeger, 1-121.

Knight, C. A. 1980. Icicles as crystallization phenomena. f. Cryst. Growth, 49, 193-198.

Laudise, R. A. and R. L. Barns. 1979. Are icicles single crystals? F. Cryst. Growth, 46, 379-386.

Leydolt, F. 1851. Beiträge zur Kenntnis der Krystallform und der Bildungsart des Eises. Sitzungsberichte der Kaiserlichen Akademie der Wissenschaften in Wien. Mathematisch-Naturwissenschaftliche Klasse, 7, $477-487$.

McConnel, J. C. and D. A. Kidd. 1888. On the plasticity of glacier and other ice. Proc. R. Soc. London, 44, 331-337.

Maeno, N. 1967. Air bubble formation in ice crystals. In Ôura, H., ed. Physics of snow and ice. International Conference on Low Temperature
Science..., 1966, Sapporo, Japan. Proceedings. Vol. 1. Sapporo, Hokkaido University. Institute of Low Temperature Science, 1, 207-218.

Maeno, N. and T. Takahashi. 1984a. Studies on icicles. I. General aspects of the structure and growth of an icicle. Low Temp. Sci., Ser. A. 43, 125-138. [In Japanese with English summary.]

Maeno, N. and T. Takahashi. 1984b. Studies on icicles. II. Wave-forms, spikes and bent icicles. Low Temp. Sci., Ser. A. 43, 139-147. [In Japanese with English summary.]

Maeno, N., L. Makkonen and T. Takahashi. 1994. Bent icicles and spikes. Ann. Glaciol., 19.

Makkonen, L. 1988. A model of icicle growth. F. Glaciol., 34(116), 64-70.

Moore, G. W. and F. S.C. Nicholas. 1964. Speleology. Boston, Heath and Co.

Tirmizi, S.H. and W.N. Gill. 1987. Effect of natural convection on growth velocity and morphology of dendritic ice crystals. F. Cryst. Growth, 85(3), 488-502.

Walker, J. 1988. Icicles ensheathe a number of puzzles: just how does the water freeze? Sci. Am., 258(5), 90-93.

Yoshida, U. and S. Tsuboi. 1929. Examination of ice-crystals by X-rays. Kyoto Imperial University. Memoirs of College of Science, A12, 203-207.

The accuracy of references in the text and in this list is the responsibility of the authors, to whom queries should be addressed. 